\title{
Erratum to: Streptomyces polyrhachii sp. nov., a novel actinomycete isolated from an edible Chinese black ant (Polyrhachis vicina Roger)
}

\author{
Chao Yu Chongxi Liu $\cdot$ Xiangjing Wang • \\ Junwei Zhao $\cdot$ Lingyu Yang $\cdot$ Ruixia Gao • \\ Yuejing Zhang $\cdot$ Wensheng Xiang
}

Published online: 2 February 2014

(C) Springer International Publishing Switzerland 2014

\section{Erratum to: Antonie van Leeuwenhoek (2013) 104:1013-1019 \\ DOI 10.1007/s10482-013-0021-3}

Subsequent to the publication of the above paper it has been brought to our attention that the species epithet proposed for the taxon represented by strain NEAU$\mathrm{ycm} 1^{\mathrm{T}}$ is not grammatically correct as "Streptomyces polyrhachii" should have been proposed as Streptomyces polyrhachis. We here propose the corrected name for the taxon represented by strain NEAU$\mathrm{ycm} 1^{\mathrm{T}}$.
Description of Streptomyces polyrhachis sp. nov.

Streptomyces polyrhachis (po.ly.rha'chis. N.L. gen. $\mathrm{n}$. polyrhachis, of the insect Polyrachis vicina Roger).

The description of the species is as given for "Streptomyces polyrhachii" in Yu et al. (2013) Antonie van Leeuwenhoek 104:1013-1019.

The type strain is NEAU-ycm $1^{\mathrm{T}}$ (=CGMCC $4.7094^{\mathrm{T}}=$ DSM $42102^{\mathrm{T}}$ ). 